\title{
Abstracts of the Emergency Medicine Research Society Conference, 25-26 November 1994, Liverpool, UK
}

\section{FREE PAPERS}

Using TRISS to measure the performance of the Helicopter Emergency Medical Service (HEMS) trauma system in groups with different probabilities of survival

P. A. YOUNGE, T. J. COATS, D. GURNEY, C. J. KIRK \& S. EVANS

Department of Accident and Emergency, The Royal London Hospital, London E1 1BB

Keywords: Revised Trauma Score, Injury Severity Score, Major Trauma Outcome Study

We measured performance of the Helicopter Emergency Medical Service (HEMS) system using TRISS compared with data from the Major Trauma Outcome Study (MTOS).

Method

Probability of survival (P) was calculated for 601 patients with blunt trauma. A standardized W statistic (W) has been proposed allowing comparison of the more severely injured HEMS group with MTOS. We also compared raw $W$ statistics for six different $P$ intervals.

\section{Results}

When TRISS is applied to MTOS data by P interval it is accurate for high and low $P$ groups but overestimates the number of survivors in the intermediate groups by as much as 14 survivors per 100. Comparison using these figures as a baseline showed significantly increased survival in three out of four intermediate HEMS $P$ intervals. There was a marked difference between the 26-50\% $P$ interval $(n=47)$ with 16.9 excess survivors per 100 (3.34 to $30.4)$ and the $51-75 \% P$ interval $(n=44)$ with no improvement over MTOS. Further analysis of case mix, injury severity scores and Revised Trauma Scores revealed interesting differences between these two groups.

\section{Conclusion}

When using TRISS, division of the study group into $P$ intervals may uncover important differences. In this analysis the $P \quad 26-50 \%$ group showed a marked increase in survival when compared to MTOS, containing more head injured patients with lower Glasgow Coma Scores, than a group which showed no increase.

A novel method for the non-invasive assessment of cerebral oxygenation during cardiopulmonary resuscitation

\section{U. M. GULY \& C. E. ROBERTSON}

Accident and Emergency Department, Royal Infirmary, Lauriston Place, Edinburgh

Keywords: CPR, cerebral oxygenation, oximetry

Hypoxic brain injury is a major factor limiting intact survival from cardiac arrest. Assessment of the effectiveness of cardiopulmonary resuscitation (CPR), or new CPR techniques, should include measurement of cerebral oxygenation. Conventional techniques used to assess cerebral perfusion are invasive and time consuming making their use impractical during CPR studies in humans. Nearinfrared optical spectroscopy allows non-invasive measurement of the regional oxygen saturation of haemoglobin $\left(\mathrm{rSO}_{2}\right)$ within the cerebral circulation. $\mathrm{rSO}_{2}$ has been found to accurately reflect mixed venous cerebral saturation. This technique has not previously been studied during CPR.

\section{Results}

We measured $\mathrm{rSO}_{2}$ in 37 patients during CPR. Of these patients $36(97 \%)$ had a mean $\mathrm{rSO}_{2}$ below $55 \%$, indicative of severe cerebral hypoxia. A total of $81 \%$ had $\mathrm{rSO}_{2}$ levels below $35 \%$ at some time during CPR. There was no significant difference in $\mathrm{rSO}_{2}$ levels between conventional and active compression-decompression CPR. Six patients regained a spontaneous circulation during the study. Four patients with a sustained return of spontaneous circulation experienced a rapid return to normal $\mathrm{rSO}_{2}$, but in two patients with a transient return of spontaneous circulation the $\mathrm{rSO}_{2}$ 
Abstracts of the EMRS

Conference, November 1994 remained low. Eight patients who had regained a spontaneous circulation following defibrillation in the community had normal $\mathrm{rSO}_{2}$.

\section{Conclusions}

Low $\mathrm{rSO}_{2}$, reflecting cerebral hypoxia is seen in most patients during both conventional and active compression-decompression CPR. Sustained return of a spontaneous circulation is associated with a return to normal $\mathrm{rSO}_{2}$. Near-infrared optical spectroscopy is a new, non-invasive method of measuring cerebral oxygenation that is suitable for use during CPR in humans. It is a promising technique that could be used to assess new CPR techniques, or to monitor the effectiveness of CPR in individual patients.

\section{Paramedic skills do not improve outcome in out-of-hospital cardiac arrest}

\section{U. M. GULY, R. MITCHELL, R. COOK \& C. E. ROBERTSON}

Accident and Emergency Department, Royal Infirmary, Lauriston Place, Edinburgh EH3 9YW

Keywords: Cardiac arrest, outcome, paramedic

Despite the increasing number of ambulance personnel being trained as paramedics in the United Kingdom there has been no objective assessment of whether the presence of paramedics at scene improves patient outcome. We prospectively studied all out-of-hospital cardiac arrests presenting to the Royal Infirmary of Edinburgh (RIE) over a 2year period to examine whether the presence of a paramedic or the use of their extended skills affected outcome. Patients whose cardiac arrest was due to a non-cardiac cause and patients treated by the Medic 1 team, an accident and emergency (A\&E) department-based medical team, were excluded from the analysis.

\section{Results}

Over a 2-year period a total of 667 patients treated in the A\&E department of the RIE following out-ofhospital cardiac arrest fulfilled the study criteria. There were 502 patients who suffered their cardiac arrest prior to the ambulance arrival in whom a record was made of whether they were treated by a paramedic or an ambulance technician.

There was no significant difference in return of survival between the two groups. The results are presented below.

\begin{tabular}{lccc}
\hline & Paramedic & $\begin{array}{l}\text { Ambulance } \\
\text { technician }\end{array}$ & $P$ \\
\hline Total number & 259 & 243 & \\
Discharged (\%) & $14(5.4 \%)$ & $23(9.5 \%)$ & n.s. (0.087) \\
\hline
\end{tabular}

Collapse-response, call-response and transport intervals were identical for both groups but the atscene interval, the collapse to hospital and call to hospital intervals were longer for patients treated by a paramedic.

Conclusion

There is no benefit from paramedic skills in the treatment of out-of-hospital cardiac arrest. The implications of paramedic use in this condition are discussed.

\section{Do paramedics save lives?}

\section{S. W. CROWDER}

Accident and Emergency Department, Royal Liverpool Hospital, Liverpool

Keywords: Out-of-hospital arrest, paramedics, survival rates

In Mersey Region, Advanced Ambulance Training began in 1987. Soon after its inception, I began a prospective, comparative study of survival, of all victims of out-of-hospital cardio-respiratory arrest brought into the Royal Liverpool Hospital. A total of 112 patients were included in two study periods, 1987-88 and 1990-91.

Of these patients, 62 were attended by conventionally-trained crews and 50 by paramedics. No attempt was made to estimate the effects of bystander resuscitation as it was almost universally absent. Response times for crews in both groups were the same but there was inevitably a delay in the patient reaching hospital in the paramedic group. Resuscitation in the accident and emergency (A\&E) department was mostly 'in-house' and was considered to be the same in both groups. The two groups were comparable in all other respects. I looked at survival to leave the A\&E department and to leave hospital as endpoints.

In the non-paramedic group 13 patients $(21 \%)$ survived to leave the A\&E department but only two (3\%) survived to leave hospital. In the paramedic 
Abstracts of the

EMRS

Conference,

November 1994 group 12 (24\%) survived through the A\&E department and five (10\%) left hospital. There were no survivors left with any significant neurological sequelae. The survival rate in the paramedic group is comparable with previous studies. There is a trend towards improved survival but this did not reach statistical significance, perhaps because the numbers were too small. The application of intubation and defibrillation did not affect survival. Whether the patient was breathing spontaneously on leaving the A\&E department indicated a higher likelihood of survival.

The use and misuse of meta-analysis

F. E. LECKY, R. A. LITTLE \& P. BRENNAN

North Western Injury Research Centre, Stopford

Building, University of Manchester, Manchester M13 9PT

Keywords: Gut-decontamination, meta-analysis, RCTs

Meta-analysis is a statistical strategy for combining the results of several studies in the hope of getting a 'statistically significant' result.

The objective of the study was to demonstrate how the results of meta-analyses can be misleading. An analysis was made of data from randomized controlled trials (RCTs) of selective gut decontamination in intensive care patients, from 23 RCTs from European Centres with different control group mortality rates.

\section{Main outcome measures}

(1) Degree of association between a trial's outcome [odds ratio (OR) of dying for treatment vs. nontreatment] and its control group mortality rate by univariate regression.

(2) Pooled OR (by the Mantel Heintzel technique) for three subgroups of trials that have similar mortality rates.

\section{Results}

(1) Regression analysis using natural logarithm (Ln) of the OR as the dependent and control group mortality as the independent variables showed a significant association. Ln OR $=0.19-(0.011 \times$ Control group mortality rate).

(2) For trials with the lowest control group mortality rate $(<20 \%)$ pooled $O R=1.13^{*}$ (treatment may do substantial harm). For trials with intermediate firms no harm or benefit). For trials with the highest rates pooled $\mathrm{OR}=0.69^{*}$ (treatment with gut decontamination may confer significant benefit). Grouping all trials $\mathrm{OR}=0.9$ (confidence interval 0.79-1.04) indicates that gut decontamination makes no difference to outcome.

\section{Conclusion}

It is meaningless to pool the results of these three subgroups of trials that come from substantially different population groups. Meta-analyses that look for statistical significance and do not take these differences into account have little clinical significance. For some 'life saving treatments' there is increasing net mortality benefit (low OR) for increasing risk of death from the condition. In emergency medicine there is an increasing number of small RCTs. Emergency physicians should resist the temptation to group the results from different patient populations, and beware the seductive numeracy of meta-analysis.

Prognostic implications of initial circulating soluble adhesion molecule soluble L-selectin and the subsequent development of the Adult Respiratory Distress Syndrome (ARDS)

S. C. DONNELLY, C. HASLETT, I. DRANSFIELD, C. E. ROBERTSON, I. GRANT, D. C. CARTER, J. A. ROSS \& T. F. TEDDER

Respiratory Medicine, Departments of Accident and Emergency Medicine and Surgery and the Intensive Therapy Unit, Royal Infirmary of Edinburgh, Lauriston Place, Edinburgh

Keywords: Adult Respiratory Distress Syndrome, neutrophil, selectins

The selectins are a family of adhesion molecules (L-selectin, E-selectin, P-selectin), all of whom are implicated in inflammatory cell transendothelial migration. They can be proteolytically cleaved from their parent cell and exist in a soluble form within the circulation. ARDS is a disease state in which neutrophils and neutrophil transeridothelial migration have been implicated. In this study we wished to investigate whether the levels of these circulating soluble receptors from patients at-risk of ARDS at initial hospital presentation, correlated with subsequent ARDS progression. Eighty-two patients were 
Abstracts of the EMRS

Conference, November 1994 enrolled, multiple trauma $(n=51)$, pancreatitis $(n=$ $19)$ and perforated bowel $(n=12)$, of whom 14 progressed to ARDS. Assays for soluble L-, P- and Eselectins were performed on collected plasma samples via a sandwich ELISA technique. Nonparametric statistical analysis was employed namely the Mann-Whitney $U$-test. Results (mean \pm SEM) are summarized below.

\begin{tabular}{lcrll}
\hline & \multicolumn{1}{l}{$\begin{array}{l}\text { ARDS } \\
\text { progression }\end{array}$} & \multicolumn{1}{l}{$\begin{array}{l}\text { No ARDS } \\
\text { progression }\end{array}$} & \\
\hline Soluble L-selectin & $0.862( \pm 0.12)$ & $2.29( \pm 0.19)$ & $\star \star \star \star$ \\
Soluble P-selectin & $190.21( \pm 17.61)$ & $154.66( \pm 9.16)$ & n.s. \\
Soluble E-selectin & $20.39( \pm 3.74)$ & $15.50( \pm 9.16)$ & n.s. \\
\hline
\end{tabular}

n.s. $=$ Not significant, ${ }^{* * * *} P=0.0001$.

We have found a highly significant inverse correlation between a low circulating SL-selectin (and not soluble E- and P-selectin) and subsequent ARDS. These results further our understanding of neutrophil endothelial interactions in the early stages of ARDS pathogenesis and offer the promise of SL-selectin in combination with other markers of inflammatory events being used to identify individuals at particularly high risk of ARDS progression on initial hospital presentation.

\section{Management of acute inversion ankle injuries in children}

\author{
A. P. GLEESON, J. STUART, B. WILSON \& \\ B. PHILLIPS
}

\section{Accident and Emergency Department, Booth Hall Children's Hospital, Manchester M9 2AA}

Keywords: Ankle injury, children, growth plate

The objective of the study was to determine whether plaster of paris (POP) or a tubular bandage is the optimal treatment for acute inversion ankle injuries in children when the clinical signs suggest a distal fibular growth plate injury, but no abnormality is visible on radiograph.

\section{Method}

A randomized prospective trial was implemented in a paediatric accident and emergency (A\&E) department. The study group comprised 45 patients presenting with an inversion ankle injury who were non-weight-bearing, had swelling and tenderness over the distal fibular growth plate, and who had a
Results

A scoring system was used to assess patients clinically at days 0,14 and 28 . The weight-bearing POP was only applied for 2 weeks. Results were analysed using Student's t-test. There was no significant difference between the assessment scores for the two groups at the three time intervals, but the tubigrip group $(n=24)$ returned to normal activity (measured in days) significantly earlier than the POP group $(n=21)(14.17 \pm 6.4$ vs. $20.19 \pm$ 3.66, $P=0.0002$ ). Patients who were shown to have a growth plate injury on ultrasound examination ( $n=19$ ) were also back to normal activity earlier when managed with a tubigrip (14.22 \pm 5.17 vs. $21.60 \pm 3.50, P=0.0032$ ).

\section{Conclusion}

Children with clinical evidence of an undisplaced Salter-Harris 1 injury to the distal fibula following inversion should be treated with a tubular bandage.

\section{Head injury, vomiting and skull fracture \\ P. A. NEE, J. M. HADFIELD, D. W. YATES \& \\ E. B. FARAGHER}

Accident and Emergency Department, Whiston Hospital, Prescot L35 5DR

Keywords: Head injury, skull fracture, vomiting

A large number of apparently mildly head injured patients present to accident and emergency (A\&E) departments each year. A small minority go on to develop intracranial complications, especially haematomas. Most of these patients have a skull fracture which has been overlooked.

\section{Methods}

In order to assess the predictive value of posttraumatic emesis as a risk factor for skull vault fracture an analysis of a consecutive series of 5415 head injured patients presenting to two A\&E departments in a 1-year study period was undertaken.

\section{Results}

The incidence of post-traumatic emesis was $7 \%$ in adults and $12 \%$ in children. In patients who had sustained a fracture of the skull vault the incidence of post-traumatic emesis was $28 \%$ in adults and $33 \%$ in children $(P=<0.001)$. In all patients an episode of vomiting was associated with a fourfold increase in relative risk (RR) of skull fracture. Multiple episodes of vomiting were no more 
Abstracts of the EMRS

Conference, November 1994 significant than a single episode. Nausea alone was not associated with increased risk of fracture. In those patients who were fully alert at presentation there was a twofold increase in RR of a fracture though statistical significance was not reached. Post-traumatic emesis was significantly more frequent after high velocity injury and with occipital impacts.

\section{Conclusions}

It is concluded that post-traumatic emesis is associated with an increased risk of fracture of the skull vault and should be an indication for radiography.

\section{A multicentre prospective study of hypothermia}

J. P. WYATT, L. HISLOP, G. MCNAUGHTON, A. IRELAND, T. RAINER, G. OLVERMAN \& L. LAWTON

Accident and Emergency Department, Royal Infirmary, Lauriston Place, Edinburgh EH3 9YW

Keywords: Hypothermia

Plans to add VAT to fuel have increased interest in hypothermia. We present the largest study to date of hypothermia in a defined population.

\section{Methods}

Patients aged over 1 year presenting with hypothermia to hospital in a continuous geographical area of S.W. Scotland (with a well-defined population of $1300000)$ were studied prospectively. The Ambulance Service and accident and emergency (A\&E) medicine trainees in all eight A\&E departments serving the area collected data during the winter (1 December 1993-31 March 1994).

\section{Results}

A total of 93 patients ( 45 male) presented with core temperatures under $35^{\circ} \mathrm{C}$. Thirty-four were severely hypothermic $\left(<32.2^{\circ} \mathrm{C}\right)$. Presentation largely reflected ambient temperatures. Alcohol was the cause implicated in 18/24 patients found outside (average age 52 years). In contrast, 69 patients found inside (66 at home) were older (average age 76 years) and had different causes (falls, poor mobility, confusion, self-neglect and various preexisting medical conditions). A total of 53/66 found at home lived alone and $\mathbf{4 2}$ had not been seen for available, $66 \%$ did not have it turned on when found.

Analysis of the 29 deaths revealed mortality rates for hypothermia at the hospitals varying from $2 / 20$ $(10 \%)$ to $8 / 11(73 \%)$. These rates were significantly different from those expected by chance (chisquared test $P<0.001$ ) and could not be explained by age or severity of hypothermia. Instead, results indicated that high mortality was related to lack of aggressive treatment.

\section{Conclusions}

The incidence of urban hypothermia presenting in winter in the UK has been defined. Isolated elderly people with social and medical problems, reluctant to heat their homes, are at risk. Possibilities for prevention exist. Some hospitals could improve treatment for hypothermia. A\&E trainees can collaborate to produce useful data!

\section{ECG features of hypothermia}

\section{G. W. McNAUGHTON}

(On behalf of the Hypothermia in Glasgow Study Group)

\section{Department of Accident and Emergency Medicine,} Western Infirmary, Glasgow G11 6NT

Keywords: ECG, hypothermia

ECG abnormalities have long been recognized in patients with hypothermia. These include arrythmias, conduction defects, shivering artefact, ST segment abnormalities and the much discussed $J$ wave. We examined the ECG tracings of a number of patients enrolled into a multi-centre prospective study of hypothermia during the winter months (December 1993-March 1994), to determine the frequencies of these abnormalities and investigate whether the ECG is of prognostic value in patients with hypothermia.

\section{Methods}

All patients presenting to six hospitals in and around Glasgow with core temperatures $<35^{\circ} \mathrm{C}$ were enrolled in the study. Baseline recordings, blood results and ECG tracings were recorded. Patients were followed up by investigators in the individual hospitals to determine the outcomes. The ECGs were reported using standard rhythm and electro-physiological parameters. 
Abstracts of the EMRS

Conference, November 1994

Results

ECG tracings were available for 73 patients (47 survivors and 26 non-survivors). Sinus rhythm was the most frequent rhythm, accounting for $54.8 \%$, atrial fibrillation was present in $23.3 \%$, conduction defects in $16.4 \%$ and profound bradycardia ( $<40$ beats $\mathrm{min}^{-1}$ ) in $5.5 \%$.

Mean PR and QRS duration were within normal limits but the mean QTc duration was significantly prolonged (481 ms). Progressive lengthening was associated with worsening prognosis. ST segment abnormalities were present in $19.2 \%$ of both survivors and non-survivors. $J$ waves occurred in $36.9 \%$ of patients overall and were more common in those with severe hypothermia. Shivering artefact was present on $56 \%$ of ECGs. There were significantly greater numbers of survivors with shivering artefact than non-survivors suggesting inability to maintain a compensatory response.

\section{Conclusion}

The ECG is rarely normal in patients with hypothermia and several features may be useful prognostic indicators.

\section{POSTERS}

\section{His Majesty's Hospital Ship 'ABA' of Liverpool}

\section{J. E. COWDEN \& A. H. MCCLELLAND}

Liverpool National Research Society, 33 Montclair Drive, Mossley Hill, Liverpool L18 OHB

Keywords: ABA, hospital ship

The Elder Dempster liner, ABA, had an eventful career. In 1917 the Tsarist Government of Russia placed an order with Barclay Curle \& Co. of Glasgow for a motor ship. Left part-completed as a consequence of the Russian Revolution, the vessel was taken over in 1918 by the Glen Line, named Glenapp, and was placed on trans-Atlantic war service. In 1921 she became the ABA of the British and African Steam Navigation Co. and was extensively re-built to become the world's first diesel propelled, ocean-going passenger liner. Placed on the West African mail service from Liverpool, the ABA proved successful.

In 1921 she towed the disabled Portuguese destroyer Guadiana for $\mathbf{4 2 2}$ miles to Las Palmas in
December 1929, she suffered storm damage to her steering gear such that she had to be towed into Cork harbour. During the 1930s the ABA spent much time laid up.

On the outbreak of the Second World War the ship was requisitioned to become an Admiralty hospital ship. Arriving at Scapa Flow in the autumn of 1939 she rendered assistance to survivors from the battleships Royal Oak and Iron Duke, which were torpedoed whilst they lay at anchor. In 1940, fully equipped as a military hospital ship, the $A B A$ took part in the Norwegian campaign. After further improvements in Liverpool she went out to the Mediterranean war zone. For 3 years she served under arduous conditions, being bombed and machine gunned in defiance of the Geneva Convention, and earning several citations for a record of achievement unequalled by any other hospital ship. All her voyages were made alone, fully lit up at night.

At the end of the war the ABA finally visited Russia. She transported severely ill Russian prisoners of war to Murmansk. Their maltreatment on arrival sickened the crew and hospital staff who were powerless to intervene. Sold in 1947 and renamed MATRONA the vessel capsized in a Birkenhead dock and was disposed of for scrap.

\section{Trauma to infants under 6 months of age}

\section{W. J. ROBSON, M. PATTERSON \& K. WILLIAMS}

Royal Liverpool Children's Hospital, Alder Hey, Eaton Road, Liverpool L12 2AP

Keywords: Accidental/non-accidental trauma, fractures, infants, shaken baby

Trauma is uncommon in infants under the age of 6 months. An audit of all admissions to the Royal Liverpool Children's Hospital, Alder Hey for one year 1991/92 was carried out.

The total number of children admitted following mechanical trauma was 1390 , of which 23 were less than 6 months of age. Of these, nine had injuries compatible with alleged accidents and six infants with fractures either had a history of nonaccidental injury or there was no history of trauma. The parents of the other eight patients gave a history which was not compatible with the findings on examination so non-accidental injury was suspected. From the analysis of the data, 
Abstracts of the EMRS

Conference,

November 1994 guidelines have been developed for the investigation of an infant with one or more fractures, or with symptoms which could result from shaking.

A comparison: lignocaine versus defibrillation, as first treatment, on survival from cardiac arrest

J. McGOWAN, M. W. G. GORDON \& N. GRIGG

Accident and Emergency Department, Southern General Hospital, Glasgow GJ1 4TF

Keywords: Cardiac arrest, defibrillation, lignocaine

In a retrospective analysis, a series of 60 consecutive patients who suffered a ventricular tachycardia or ventricular fibrillation cardiac arrest, and who were expected to live prior to their arrest, was compared. Fifteen of these patients were initially treated with Lignocaine $100 \mathrm{mg}$ intravenously. Forty-five patients were initially treated with a 200J. DC8 shock. The 15 patients given lignocaine were all subsequently defibrillated. Of these 15 patients, 10 (67\%) survived their cardiac arrest, but only three (20\%) survived to discharge from hospital. Of the patients initially defibrillated, 37 (82\%) survived their arrest and 24 (53\%) were discharged from hospital. The difference in survival (significant at the $5 \%$ level) would suggest that treatment with lignocaine prior to defibrillation should be avoided. Analysis of the timing of deaths in those patients treated initially with lignocaine, who survived their cardiac arrest, shows a mean survival of 4.7 days ( 0.31 to 17 days) suggesting a late effect from treatment with this drug.

\section{Handbooks for senior house officers: how essential are they to a learner-centred educational system?}

\section{A. E. ROBINSON ${ }^{1}$ \& G. J. PARSELL ${ }^{2}$}

'Accident and Emergency Department, Warrington Hospital NHS Trust and ${ }^{2}$ Medical Education Unit, Faculty of Medicine, University of Liverpool

Keywords: Education, handbook, training

Since 1 October 1992, five departments in Warrington Hospital have been involved in a project to improve education and training for senior house officers (SHOs).
An audit of learning activities was first carried out by an external evaluator. The audit identified good practice and areas where improvements might be made. Consultants in these departments collaborated to develop an educational system based on principles of adult learning which were incorporated in an SHO Handbook and Training Record. This poster focuses on the introduction and implementation of the education system into the accident and emergency (A\&E) department at Warrington Hospital, findings of the education audit and the role of SHOs and senior staff in directing change.

\section{Method}

To evaluate the impact of the system and the use of the handbooks, interviews were carried out with SHOs after 2 months and by completing anonymous questionnaires at the end of their 6-month posts.

\section{Conclusions}

Findings indicate, that extensive training is needed in new approaches to teaching andlearning for all medical staff who are involved in the clinical activities of SHOs, if opportunities for learning are to be used effectively.

\section{Evaluation of cardiopulmonary resuscitation using video camera recordings}

\section{J. MANN \& J. HEYWORTH}

Department of Accident and Emergency Medicine, Queen Alexandra Hospital, Cosham, Portsmouth P06 3LY

Keywords: Cardiac arrest, resuscitation, video

Internationally recognized protocols have led towards a standardized approach to cardiopulmonary resuscitation using validated techniques. Using a video record to evaluate compliance with protocols during the resuscitation of victims of outof-hospital cardiac arrest in an accident and emergency (A\&E) department has demonstrated that the video is a valuable tool for performance review, audit and training.

Analysis of 67 resuscitations was made. The findings identify specific problems both with individual skill levels and with team composition and organization.

Comparison of resuscitations led by Advanced Cardiac Life Support-trained (ACLS) and non ACLS-trained doctors demonstrates an improved performance in achieving the key interventions of 
Abstracts of the EMRS

Conference,

November 1994 rapid defibrillation and central administration of adrenaline. The results are presented below.

\begin{tabular}{lcl}
\hline & A\&E staff & Cardiac arrest team \\
\hline Survival to discharge & 1 & 1 \\
Survival beyond A\&E dept & 10 & 0 \\
Doctors & 2.6 & 3.2 \\
Nurses & 4 & 2.7 \\
Time for three shocks & $54 \mathrm{~s}$ & $83 \mathrm{~s}$ \\
Central venous access & $42(90 \%)$ & $4(25 \%)$ \\
ALS-trained nurses & 1 & 1 \\
ALS-trained doctors & 1.5 & 0 \\
Registrar or above & 1 & 0 \\
\hline
\end{tabular}

It is concluded that the video is a useful tool and has highlighted the value of advanced cardiac life support training.

\section{Improvements in trauma survival in Leeds}

P. BURDETT-SMITH, M. AIREY \&

A. FRANKS

The Royal Liverpool University Hospital, Prescot Street, Liverpool L7 8XP

Keywords: ISS, major trauma

A total of 186 cases of major trauma [injury severity score (ISS) greater than 15] admitted to two Leeds hospitals in the year 1988-89 were compared with 198 cases admitted in 1992-93, in order to ascertain whether a system of trauma care, which had evolved in the hospitals during this time, had affected the outcome of these patients.

Injury severity score, age and sex distribution were similar for the two groups. There were significantly fewer deaths in 1992-93, particularly in those patients with an ISS of less than 41.

It would appear that the emphasis since 1988 on timely and definitive management of patients with major trauma has led to improved survival of the seriously injured in Leeds.

An analysis of the effects of British Summer Time on road traffic accidents in the Chester area

\section{J. WHITTAKER}

Accident and Emergency Department, Countess of Chester Hospital, Chester

Keywords: British Summer Time, road traffic accident
In the light of recent calls for the introduction of year round British Summer Time (BST), the object of this study was to establish whether the annual change to British Summer Time had a discernible effect on the types and frequencies of road traffic accidents (RTAs) in the Chester area.

\section{Methods}

Data were obtained from a database of police accident reports. An 11-year period was chosen and RTAs were analysed from a 2-week period either side of the change in hours in the spring and autumn. Analysis concentrated on the daily peaks in RTAs in the morning and evening and thus a total of 4185 casualties were studied.

\section{Results}

It was found that the onset of BST in March was associated with a significant reduction in the total numbers of RTAs with specific reductions in the frequency of both pedestrian and vehicle accidents. The reversion back to Greenwich Mean Time in October was not associated with any concomitant increases in accidents in any group.

\section{Discussion}

The central position of Chester in the UK and its mixture of rural and urban areas provides a benchmark for the countrywide situation. The anticipated increase in the frequency of RTAs with darker mornings and evenings in the spring and autumn was not seen.

\section{Conclusion}

It is proposed that setting the clocks forward by $1 \mathrm{~h}$ in the spring has a beneficial effect on RTA incidence in the Chester area and that the introduction of year-long BST may result in an overall reduction in RTAs.

\section{Evaluation of outcome following pre-hospital cardiac arrest in patients presenting to two Scottish accident and emergency departments}

T. RAINER, M. GORDON, C. ROBERTSON \& S. CUSACK

Accident and Emergency Departments, Glasgow and Edinburgh Royal Infirmaries

Keywords: Pre-hospital cardiac arrest, outcome

The objectives of the study were to compare and contrast outcome following cardiac arrest in two of Scotland's busiest accident and emergency (A\&E) 
EMRS

Conference, November 1994
Abstracts of the

departments, and to identify factors which might account for such differences.

\section{Methods}

A prospective 1-year evaluation (1 January31 December 1991) was carried out using a pro forma that was completed for all patients sustaining a pre-hospital cardiac arrest. The A\&E departments of the Edinburgh (ERI) and Glasgow (GRI) Royal Infirmaries serve two large urban municipalities with populations of 750000 (ERI) and 200000 (GRI). All patients sustaining a pre-hospital cardiac arrest and brought to ERI or GRI were included. Children (<13 years), those declared dead on arrival at scene, and those arrests associated with poisoning, near drowning, trauma and pregnancy were excluded.

Patients were followed up for 3 months. Outcome was assessed for: (1) death in the A\&E department, (2) admission to a ward, and (3) alive to discharge or 3 months post-discharge.

Descriptive analysis was carried out using nonparametric methods, Chi-squared test for analysis of categorical variables and Mann-Whitney $U$-tests for continuous variables.

\section{Results}

There were 297 pre-hospital arrests from ERI, and 158 from GRI. Eighty-two people (27.6\%) were admitted as in-patients to ERI and $23(14.6 \%)$ to GRI $(P<0.01)$. Thirty-nine patients $(13.1 \%)$ survived to hospital discharge from ERI and $13(8.2 \%)$ survived to discharge from GRI (n.s.). The proportion of VFNT:Asystole observed was significantly different between the two centres - 162:98 from ERI, 54:73 from GRI $(P<0.001)$. More pre-hospital arrests were witnessed and received bystander CPR in ERI $(P<0.02)$. Ambulance response times from ERI were significantly shorter $(P<0.01)$. Two survivors from ERI had asystole as their initial observed rhythm. From GRI, one survivor had asystole and one had electromechanical dissociation. No survivor to discharge had severe neurological disability.

\section{Conclusions}

Patients suffering out-of-hospital cardiac arrests in Edinburgh have a significantly better chance of being admitted to a ward. Trends favour better survival to discharge in Edinburgh. Fewer witnessed arrests, less bystander CPR and slower ambulance
There is a need to investigate the environment in which patients collapse, to train the public in CPR, and to review the efficiency and resourcing of the ambulance service.

The accident and emergency training logbook: is training up to it?

\section{THE MERSEY ACCIDENT AND EMERGENCY TRAINEES GROUP}

(Correspondence to T. Good)

\section{Royal Liverpool University Hospital, Prescot Street, Liverpool L7 8XP}

Keywords: Accident and emergency, curriculum, logbook, training

The objective of the study was to make an early assessment of an accident and emergency (A\&E) higher specialists training logbook.

\section{Methods}

A questionnaire-based survey was made of nine A\&E medicine trainees using The Mersey Region Accident and Emergency Specialist Training Logbook. Twenty-one questions were asked encompassing the style, contents, use and value of the Logbook as well as inviting general comments and others relating to specific questions.

\section{Results}

The clinical curriculum-based sections together with management, education and research curricula were considered to be adequate to good in content. In general there was considered to be no section missing from the book and none that should be excluded.

Aims and objectives for planning secondments were considered to be the most useful part of the Logbook however difficulties were still experienced with secondment planning and supervision which the Logbook highlighted but could not compensate for. The Logbook was considered to be a valuable record of training. It was used but was not in general kept up to date at the filling-in sections. Comments and recommendations were made regarding the binding and ease of use. In general comments on its value were favourable.

\section{Conclusions}

The Mersey Logbook achieves its objectives as a curriculum based guide to Specialist A\&E training. Its limitations are in the practical execution of its 
Abstracts of the EMRS

Conference, November 1994 objectives and hence the limitations of training. It is therefore not only of benefit to planning training but through its feedback sections monitoring A\&E curriculum received by trainees. This assessment of weaknesses in training programmes can provide the organizers and supervisors of A\&E specialist training with feedback and direction for improvement.

\section{The relationship between the Glasgow Coma Score and the cough reflex}

\section{MOULTON \& A. PENNYCOOK}

Stockport Infirmary, Wellington Road South, Stockport SK1 3UJ

\section{Keywords: Cough reflex, Glasgow Come Score}

The objectives of the study were to discover what relationship, if any, exists between the level of consciousness [as defined by the Glasgow Coma Score (GCS)] and the state of the cough reflex. Observational recordings were made by two doctors participating in the patients' treatment with no change to any routine practice. The study group comprised 76 patients presenting to the accident and emergency (A\&E) department in coma of any cause $(\mathrm{GCS}=\mathrm{OR}<8$ ).

\section{Main outcome measures}

The state of the cough reflex was graded as normal, attenuated or absent. The GCS and the cause of the coma were also noted.

\section{Results}

The state of the cough reflex was found to bear no fixed relationship to conscious level as defined by GCS in comatose patients presenting to the A\&E department.

\section{Conclusions}

All comatose patients presenting to the A\&E department must be treated as if their airway is at risk. However, even at the lowest levels of the GCS there are many patients whose airway reflexes are sufficiently intact to make procedures such as endotracheal intubation difficult or dangerous without the use of drugs. The state of the airway should thus be assessed independently of

\section{PRIZE SESSION}

The temporal distribution of deaths following trauma

J. P. WYATT, D. BEARD, A. GRAY, A. BUSUTTIL \& C. E. ROBERTSON

Accident and Emergency Department, Royal Infirmary, Lauriston Place, Edinburgh EH3 9YW

Keywords: Trauma deaths

The concept of a trimodal distribution of deaths following trauma, based on US data published by Trunkey in 1983, is widely quoted. This study examines whether a similar phenomenon exists in the UK.

\section{Methods}

All patients aged over 12 years who died following trauma in S.E. Scotland during a 2-year period (1992-1994) were identified from forensic medicine, police and hospital records and from the Scottish Trauma Audit Group. The same criteria for inclusion as those used by Trunkey were employed. Age, sex, times to death, ISS, RTS and Ps were recorded.

Results

A total of 331 patients (244 male) died following trauma (22 penetrating trauma, 309 blunt trauma). The largest proportion comprised 125 patients who died after road traffic accidents. There were 98 suicides and 26 murders. A total of 253 patients $(77 \%)$ died within $1 \mathrm{~h}, 248(98 \%)$ of these either died instantly or were found dead. When plotted against time, subsequent deaths do not fall into 'peaks'. Forty-five patients (14\%) died between 1 and $4 \mathrm{~h}$ after trauma; 33 (10\%) died more than $4 \mathrm{~h}$ later.

\section{Conclusions}

UK trauma deaths differ from those in the US in several ways, with fewer murders and fewer penetrating injuries. This study does not support the concept of a trimodal distribution of trauma deaths in the UK. The first and only 'peak' was much larger than the $50 \%$ reported by Trunkey 11 years ago. Possible reasons will be discussed.

The philosophy accompanying the trimodal distribution of trauma deaths has placed greatest emphasis on prevention of 'unnecessary deaths', particularly in the 'second peak', by improving treatment. This study suggests that there is less oppor- 
Abstracts of the EMRS

Conference, November 1994 tunity for saving lives by improving treatment than might be expected. Whilst efforts to improve treatment and outcome must and will continue, it should be recognized that the greatest potential now lies with prevention.

Phagocytic function after haemorrhage and resuscitation: modulation by different fluids

J. J. WARD, E. A. M. VAN RIJEN,

E. KIRKMAN, I. V. HUTCHINSON \&

R. A. LITTLE

North Western Injury Research Centre, University of Manchester M13 9PT

Keywords: Haemaccel, haemorrhage, hydroxyethyl starch, phagocytic function, resuscitation

Many of the late deaths following trauma can be attributed to the development of sepsis and the systemic inflammatory response syndrome (SIRS). It is probable that the initiation of SIRS occurs early after trauma following inadequate or inappropriate resuscitation. For example, it is known that resuscitation fluids including blood can modulate the immune system (Schildt et al. 1975: Acta Chir Scand 141, 7; Opelz et al. 1973; Transplant Proc 5, 253). One facet of this system is the ability of the reticuloendothelial system (RES) to clear particles (including bacteria) from the blood. Using a previously described experimental model (van Rijen et al. 1994: Shock 2, Suppl. 21), the effect of three resuscitation fluids, Haemaccel, hydroxyethyl starch (HES) and fresh autologous blood on RES function (measured as phagocytic index, K) after a $40 \%$ haemorrhage in Balb/c mice at 1, 6, 24, 48 and $72 \mathrm{~h}$ after the end of haemorrhage was investigated. The mice, anaesthetized with isoflurane were bled over a 10-min period, left hypovolaemic for $30 \mathrm{~min}$, and then resuscitated with their shed blood or the same volume of asanguinous fluid. The values obtained for $\mathrm{K}$ at the different times were compared with values from appropriate sham-operated (no haemorrhage) animals using a two-way analysis of variance (ANOVA) $(P<0.05)$. Provided the mice were maintained normothermic, the expected acute (1-6h) depression (Altura 1974; Circ Shock 1, 295) in RES function after haemorrhage and resuscitation was not seen, indeed no significant change in $K$ was found at any time in animals resuscitated with blood. However, following resuscitation with artifi- cial colloids, significant increases in $\mathrm{K}$ were found (HES at 48h; Haemaccel at 24, 48 and $72 \mathrm{~h}$ ).

Before any clinical implications are suggested, the cellular mechanisms of this modulation must be investigated.

An assessment of the value of CK-MB and CKMM isoforms in the evaluation of chest pain in the accident and emergency department

U. GEARY, N. ROBERTS, P. MULLINS \&

L. C. LUKE

Royal Liverpool University Hospital, Prescot Street, Liverpool

Keywords: Chest pain, CK-MB

Chest pain is a clinical condition fraught with hazards for clinicians within the accident and emergency (A\&E) department setting and undiagnosed cases of myocardial infarction remain a leading reason for malpractice litigation. Emergency physicians have long recognized the need for adjunctive tests in the early investigation of patients with chest pain and CK-MM and CK-MB isoform analysis has recently been proposed as such a test. This study attempted to perform a preliminary assessment of the practical value of isoform enzyme analysis in a typical United Kingdom A\&E department in the identification of patients with acute myocardial infarction (AMI).

\section{Setting}

This preliminary study was based in a large urban University Hospital A\&E department with an annual new patient attendance of 85000 per annum (previous audit had identified chest pain to be the presenting complaint in approximately $2 \%$ of these attendances). All patients who presented over a period of 6 weeks with potentially cardiogenic chest pain as their primary complaint were included in the study. A blood sample taken at the time of initial assessment was analysed for CK-MM and CK-MB isoforms by high voltage electrophoresis using the Cardio-Rep system (Helena Labs).

\section{Results}

A total of 54 patients were investigated with isoform analysis and sample profiles provided early confirmation of a clinical diagnosis of myocardial infarction in the majority of cases. In a further five cases isoform analysis indicated myocardial infaraction where this was thought to be unlikely by attending 
Abstracts of the EMRS

Conference, November 1994 physicians. The isoform test failed to show evidence of infarction in two subsequently proven cases of AMI and this was attributed to premature sampling. In general the analysis of isoforms profiles within $4 \mathrm{~h}$ was felt to be less reliable than that performed at least $6 \mathrm{~h}$ after the onset of symptoms.

\section{Conclusions}

The analysis of CK-MM and CK-MB isoforms is now relatively simple to perform and appears to offer a valuable adjunct to the clinician in the $A \& E$ department. Preliminary assessment suggests that it will enhance early and accurate diagnosis of myocardial infarction provided that $6 \mathrm{~h}$ are allowed from the onset of symptoms for isoform profiles to develop.

Is $\mathrm{SaO}_{2}$ a valid measure of well-being in the critically ill?

\section{R. G. MITCHELL \& C. E. ROBERTSON}

Department of Accident and Emergency Medicine, Royal Infirmary, Lauriston Place, Edinburgh EH3 gYW

Keywords: Critically ill patients, haemodynamics, pulse oximetry

The objectives of the study were to determine the value of peripheral $\mathrm{SaO}_{2}$ measurement in critically ill and injured patients.

\section{Method}

A prospective study was made of all patients admitted to the Resuscitation Room. Measurements of peripheral oxygen saturation $\left(\mathrm{SaO}_{2}\right)$, pulse rate, non-invasive and invasive blood pressure and simultaneous measurement of arterial blood gas tensions were taken. The study was carried out in a University Teaching Hospital, accident and emergency (A\&E) department. The study group comprised 200 consecutive patients triaged to the Resuscitation Room with life-threatening medical, surgical or trauma presentations.

\section{Results}

No correlation was demonstrated between heart rate, systolic or diastolic blood pressure and $\mathrm{SaO} 2$ measurement. Of patients, $15 \%$ had significant desaturation $\left(\mathrm{SaO}_{2}<90 \%\right)$, but $42 \%$ of these had a $\mathrm{PaO}_{2}>10 \mathrm{kPa}$. There was no correlation between $\mathrm{PaCO}_{2}$ and $\mathrm{SaO}_{2}$. Of patients, $16 \%$ had a $\mathrm{PaCO}_{2}>$ $9 \mathrm{kPa}$, however of these only $28 \%$ had a corre- the sub-group of patients with indwelling intraarterial lines, blood pressure was monitored simultaneously via a pressure transducer and a standard sphygmomanometer cuff, a good correlation was found in both systolic and diastolic pressures ( $r=0.88$ and 0.95 respectively).

\section{Conclusions}

Peripheral oxygen saturation measurement is a poor guide to the severity of physiological disturbance in critically ill patients, and correlates poorly with other commonly used parametes. In particular patients with respiratory dysfunction and hypercapnoea may have misleadingly 'normal' $\mathrm{SaO}_{2}$ values that can be misconstrued as indicating well-being.

\section{Ultrasound assessment of childrens' ankle injuries}

\section{J. STUART, A. GLEESON, B. PHILLIPS \& B. WILSON}

\section{Accident and Emergency Department, Booth Hall Children's Hospital, Manchester M9 2AA}

Keywords: Diagnostic ultrasound, growth plate injury, inversion ankle injury

The objectives of the study were to determine, by using diagnostic ultrasound, whether children who exhibit signs of bony injury following acute inversion ankle injury, but who have a normal radiograph, in fact do have evidence of bony injury.

\section{Method}

A prospective study was made of $\mathbf{4 0}$ patients with clinical signs of bony injury, but with a normal radiograph following acute inversion ankle injury.

Forty patients, attending the accident and emergency (A\&E) department of a childrens' teaching hospital were studied. All patients had clinical signs of bony injury, normal radiograph and a patent growth plate following acute inversion ankle injury.

\section{Results}

A total of $57.5 \%$ patients had a subperiosteal haematoma adjacent to or straddling the lower fibular growth plate, $45 \%$ had swelling of the peroneus longus tendon, $15 \%$ had widening of the lower fibular growth plate, $7.5 \%$ had evidence of venous stasis and $7.5 \%$ had a joint effusion.

\section{Conclusion}

Children who exhibit signs of bony injury following acute inversion ankle injuries, despite a normal radiograph, are likely to have evidence of this on ultrasound. 